\title{
Sustainable low-temperature asphalt mixtures with marginal porous volcanic aggregates and crumb rubber modified bitumen
}

\author{
Miguel A. Franesqui ${ }^{\text {a, * }}$, Jorge Yepes ${ }^{\text {b }}$, Cándida García-González a , Juan Gallego c \\ a Grupo de Fabricación Integral y Avanzada, Departamento de Ingeniería Civil, Universidad de Las Palmas de Gran Canaria (ULPGC), Campus de Tafira, \\ 35017 Las Palmas de Gran Canaria, Spain \\ ${ }^{\mathrm{b}}$ Departamento de Ingeniería Civil, IOCAG, Universidad de Las Palmas de Gran Canaria (ULPGC), Campus de Tafira, 35017 Las Palmas de Gran Canaria, \\ Spain \\ ' Grupo de Investigación en Ingeniería de Carreteras, Departamento de Ingeniería Civil, Transporte y Territorio, Universidad Politécnica de Madrid (UPM), c/ \\ Profesor Aranguren s/n, 28040 Madrid, Spain
}

Keywords:

Low-temperature mixture

Warm mix asphalt (WMA)

Volcanic aggregate

Vesicular basalt

Asphalt-rubber (AR)

Reclaimed tyre rubber

End-of-life tyre (ELT)

Surfactant additive

\begin{abstract}
A B S T R A C T
This study presents the results of the principal engineering properties of asphalt-rubber warm mixtures (AR-WMA) with waste crumb rubber from used tyres and highly-vesiculated basalt of scoriaceous nature, also considered a residual or marginal aggregate according to standard specifications. The temperature reduction was carried out using a liquid surfactant chemical additive, of easier dosage than granular solid products and in a reduced proportion ( $0.5 \%$ by weight of bitumen). The results were compared both to asphalt-rubber hot mixtures and to hot mixtures with conventional bitumen, all of them with the same aggregates. With the surfactant additive it is possible to lower the production temperatures by up to a maximum of $5-10^{\circ} \mathrm{C}$ complying with all the technical specifications for surface courses of pavements, and by up to $25-30^{\circ} \mathrm{C}$ for inferior layers or in case of more lenient requirements. Even in the first case, it may compensate for the increase of energy and emissions due to the higher viscosity of the asphaltrubber binder. With a temperature reduction of $40^{\circ} \mathrm{C}$, certain properties such as the moisture damage strength ratio, rutting resistance and stability were even superior compared to conventional mixtures without rubber (produced at $170^{\circ} \mathrm{C}$ ). The results obtained may be extrapolated to other volcanic regions both insular and continental areas where this type of aggregates are commonly found and with rigorous environmental requirements.
\end{abstract}

\section{Introduction}

Long-term sustainability of asphalt pavements requires techniques that allow longer on-service life of the materials and so reduce the total costs during their life cycle. It is also fundamental to use local aggregates and materials, reuse and recycle residual products as well as employing low-consumption technologies of raw materials and energy that reduce emissions and waste.

In volcanic territories the most common and abundant aggregates are obtained from eruptive rocks and lava flows with a vesicular and scoriaceous structure of high porosity. However, the higher absorption due to the alveolar structure, particle shape and heterogeneous properties make these aggregates marginal and

Corresponding author.

E-mail address: miguel.franesqui@ulpgc.es (M.A. Franesqui). inadequate for structural materials according to standard technical specifications (Franesqui et al., 2010). Hence, this type of aggregates offer inferior performance and limits the use in structural concretes and bituminous mixtures.

In a similar way, the waste from used tyres has also become an important environmental issue in volcanic island territories with natural areas of great value and therefore reuse in situ becomes vital. The recycling of crumb rubber from reclaimed end-of-life tyres (ELT) used as a modifier of the asphalt binder (crumb rubber modifier or CRM) for bituminous mixtures is an interesting alternative. Asphalt-rubber (AR), also called "wet process", is the blend of an asphalt binder and ground recycled tyre rubber from scrap ELT in which the rubber powder reacts in the hot asphalt bitumen sufficiently to cause swelling of the rubber particles. AR mixtures offer certain environmental advantages regarding natural resources as well as traffic noise reduction. They also provide improved pavement performance properties: moisture sensitivity, 
rutting resistance and Marshall stability (Liu et al., 2009; Moreno et al., 2013; Shu and Huang, 2014; Kakar et al., 2015; Gibreil and Feng, 2017). This reduces maintenance costs and increases durability. However, the production and compaction temperatures of asphalt-rubber hot mixtures (AR-HMA) are usually at least $10-15{ }^{\circ} \mathrm{C}$ higher than with conventional binders as the rubber lends to a greater viscosity. This is due to the digestion process of the rubber in the bitumen (Wang et al., 2017), and thus it reduces workability, decreases the laying and compaction time and increases costs (Lo Presti, 2013). This is an important drawback of this technology as it produces higher energy consumptions $(0.5-1.0 \mathrm{~L} /$ tonne more) and emissions (1.3-2.5 kg- $\mathrm{CO}_{2} /$ tonne more), which compromises its environmental sustainability. Therefore, in order to guarantee eco-efficiency, AR mixtures should inevitably be associated with warm mix asphalt technologies (AR-WMA) without significantly affecting the mechanical performance.

Of all the methodologies utilized to reduce the manufacturing temperatures of bituminous mixtures that do not use water during the process, the techniques that use microcrystalline waxes to decrease the bitumen viscosity have been thoroughly tried and tested. Most of them are patented products that can improve the binder fluency and reduce the production temperatures by 20-30 ${ }^{\circ} \mathrm{C}$ (Kakar et al., 2015; Rondón-Quintana et al., 2015). Wax additives have also been used in order to reduce the production temperatures of AR mixtures (Rodríguez-Alloza and Gallego, 2017; Saberi et al., 2017) even with reclaimed asphalt pavement (RAP) (Saberi et al., 2017), providing improved performance against moisture susceptibility, fatigue cracking and permanent deformation. In addition, asphalt-wax mixes enable energy saving and reduce emissions (Rodríguez-Alloza et al., 2015) and pollutant fumes (Autelitano et al., 2017).

On the other hand, the tensioactive chemical additives raise the surfactant capacity of the binder with the aggregates. There are also numerous adhesion promoters (anti-stripping surfactant agents or cationic emulsification agents) that allow lower manufacturing temperatures; between 15 and $30^{\circ} \mathrm{C}$ (Xiao et al., 2012; RondónQuintana et al., 2015). These products contribute to an efficient coating of the asphalt binder on the aggregate surface by reducing the surface tension of the bitumen, increasing the mixture workability and compactability at lower temperatures (Jamshidi et al., 2015; Li et al., 2016; Yang et al., 2017). Consequently, contaminant emissions are reduced and, in certain cases, the bitumen consumption. Although the manufacturers, due to patent policies, do not always offer sufficient information regarding composition or characteristics (Bonaquist, 2011; Rondón-Quintana et al., 2015), in some previous studies with certain additives, it has been verified that resistance to permanent deformations and dynamic resistance of mixtures are maintained or improved (Ouni et al., 2014; Yang et al., 2017). They can also increase resistance to moisture action owing to the presence of polymers within the composition (Rondón-Quintana et al., 2015). been:

However, the main limitations of the previous studies have

a) Despite the quantitative importance of the marginal volcanic aggregates in many regions, these are usually discarded at the quarries as there are very few studies regarding their applications in bituminous mixtures and these only refer to certain lithotypes such as trachybasalts and volcanic ashes (Faustino et al., 2005; Naji and Asi, 2008; Akbulut et al., 2011). Furthermore, most technical regulations do not usually include specifications adapted to the peculiarities of these mixtures but in volcanic areas the use of these local aggregates is a necessity.

b) There are no studies regarding the performance of asphalt mixtures with high-porosity vesicular and scoriaceous basaltic rock as the main mineral aggregate even though these are readily available. In the same way, there are no studies regarding the effect of the AR binders on these porous aggregates or about the possibility of manufacturing these mixtures at low temperatures. Moreover, the use of marginal aggregates does not usually meet the standard specifications for road pavements due to certain performance properties of these mixtures.

c) Organic additives for WMA of the type microcrystalline waxes are expensive as they are required in high quantities (up to $2-4 \%$ by bitumen weight) and some crystalize below certain temperatures (Sánchez et al., 2011; Rodríguez-Alloza et al., 2014). This makes the asphalt mixture stiffer and more difficult to compact and consequently more susceptible to lowtemperature cracking (Edwards and Redelius, 2003). They may even worsen fatigue resistance at medium or low temperatures (Rondón-Quintana et al., 2015).

The previous state of the art determined that our study focuses on the use of elastomeric residuals from ELT in order to modify the asphalt bitumen and improve the performance of bituminous mixtures with marginal volcanic aggregates with high degree of vesiculation; the primary aim being to remediate both residuals, reduce the environmental impact and improve pavement durability. Likewise, the use of CRM in the binder composition could compensate for the higher amount of asphalt bitumen required when using high porosity aggregates. In order to meet the environmental challenge implied in the use of AR binders, the temperature reduction is studied by using a tensioactive chemical additive with surfactant properties and with the following characteristics: a) useable in reduced proportions (no higher than $0.5 \%$ by weigh of the binder, in order to be economically feasible in large pavement production); b) allowing an easier dosage added in a liquid state; c) does not cause crystallization below certain temperatures, as occurs with waxes, achieving higher densities and improved properties for the mixtures.

In order to confirm the practical effectiveness of this solution the main engineering properties of AR mixes with volcanic aggregates from high-porosity vesicular and scoriaceous basalt (6-16\% of water absorption) and produced at different low temperatures by using a surfactant liquid additive, were characterized in the laboratory. These are compared both to the AR mixtures manufactured at high temperature and to the hot mixes produced with conventional bitumen and the same volcanic aggregates.

\section{Experimental method}

\subsection{Materials}

228 cylindrical specimens, 32 slab specimens and 30 noncompacted samples (for theoretical maximum density tests) were produced in the laboratory, including the reference hot mix asphalt without rubber (Ref. HMA), the reference hot mix asphalt with asphalt-rubber binder (Ref. AR-HMA) and the asphalt-rubber mixtures with warm mix asphalt additive (AR-WMA); these all consisted of semi-dense asphalt concrete (AC16 surf S). This type of paving asphalt concrete was produced following the Spanish technical specifications for roads (PG-3) (Spanish Ministry of Infrastructures, 2014) and is in accordance with European Standard EN 13108-1. This bituminous mixture is widely used for surface courses of different roads, traffic types and climates. It provides better surface macrotexture, lower susceptibility to permanent deformations and is more economical than dense asphalt concrete.

All aggregate fractions used in the mixtures (10-20, 4-10 and 0-4 mm) come from the same type of volcanic rock obtained in the same quarry in Gran Canaria (Canary Islands, Spain). This quarry is 
exploited by the Port of Las Palmas to obtain filling material for harbour works. The type of all-in aggregate is a mechanicallycrushed vesicular olivinic-piroxenic grey basalt (B-V) of high porosity, one of the most common and abundant lithotypes of rocks in volcanic territories (Franesqui et al., 2010). The main properties are summarized in Table 1 and a detail may be observed in Fig. 1. This vesiculated aggregate with scoriaceous structure presents a high water absorption $\left(\mathrm{WA}_{24}\right)$, particularly in the finest fraction (15.5\%). The flakiness index (FI), the sand equivalent of fraction $0-4 \mathrm{~mm}\left(\mathrm{SE}_{4}\right)$ and the polished stone value (PSV) complied with the Spanish specifications for road pavements ( $\mathrm{FI} \leq 20-30$; $\mathrm{SE}_{4}>55 ; \mathrm{LA} \leq 20-25 ; \mathrm{PSV} \geq 50-56$ ). These technical specifications are very similar to other international regulations. However, this volcanic aggregate is considered marginal owing to its high percentage of non-prismatic particles, the values of resistance to fragmentation (Los-Angeles coefficient, LA) and resistance to wear (Micro-Deval coefficient, $\mathrm{M}_{\mathrm{DE}}$ ).

A Portland cement with pozzolanic addition, type CEM II/B-P 32.5 R (according to EN 197-1) was used as mineral filler $(\#<0.063 \mathrm{~mm})$. This cement is commonly produced in volcanic areas as natural pozzolans are easily found.

The reference mixture without rubber used a commercial bitumen 35/50 pen, whilst the binder of the mixtures with rubber was an asphalt-rubber of the same penetration grade (AR35/50), produced in the laboratory by adding the crumb rubber modifier (CRM). The CRM was manufactured by mechanical grinding at ambient temperature (50\% from used truck tyres; $50 \%$ used car tyres). To ensure consistency, only one batch of CRM was used. The thermogravimetric analysis revealed the following composition: $57.41 \%$ polymer (rubber), $32.22 \%$ carbon black, $6.02 \%$ ash and $4.67 \%$ plasticizer and additives. $100 \%$ by weight of CRM passed through sieve $1.0 \mathrm{~mm}$ (EN 933-2), 94.1\% accumulated of a size smaller than $0.5 \mathrm{~mm}, 23.7 \%$ smaller than $0.25 \mathrm{~mm}, 3.7 \%$ smaller than $0.125 \mathrm{~mm}$ and $0.4 \%$ smaller than $0.063 \mathrm{~mm}$. The main properties of the binders used for the different types of mixtures are included in Table 2.

The surfactant chemical additive employed to reduce the mixing and compaction temperatures was Cecabase $\mathrm{RT}^{\circledR}$ (Arkema Innovative Chemistry, France), a commercial liquid water-free tensioactive product (see Fig. 2) composed of at least $50 \%$ renewable components. The main physical properties are: viscosity at $25^{\circ} \mathrm{C}$ : $600 \mathrm{cP}$; density: $0.997 \mathrm{Mg} / \mathrm{m}^{3}$; freezing point: $-10^{\circ} \mathrm{C}$; flash point: $>200^{\circ} \mathrm{C}$; readily soluble in asphalt binder.

\subsection{Methodology}

In order to compare the effect of the AR binder as well as the temperature reduction additive on the properties of this semidense asphalt concrete with highly-vesiculated basalt, three types of mixtures were formulated in the laboratory:

1) In the initial phase, the reference hot mixture (Ref. HMA) specimens of the type AC16 35/50 surf S with 6\% (by total weight of mix) of conventional bitumen 35/50 pen were manufactured and tested. Previous Marshall tests, ITSR tests and wheel tracking tests showed this was the optimum binder content according to the resulting properties related to density, air voids, stability, flow value, resistance to water damage and rutting resistance of the mixtures.

2) In the next phase, the reference asphalt-rubber hot mixture (Ref. AR-HMA) specimens (AC16 AR35/50 surf S) were produced and tested. These were manufactured with the same type of aggregate, identical particle size distribution (Table 3) and binder content (6\%), because laboratory tests shown no significant differences between the optimal binder contents of Ref. HMA and Ref. AR-HMA. However, these last mixtures were made with an AR binder of similar penetration grade (Table 2), previously manufactured in the laboratory by mixing the CRM with a bitumen 50/70 pen. The AR35/50 was obtained with the bitumen 50/70 pen because the elastomer increases the viscosity and consistency of the resulting binder.

3) Finally, the asphalt-rubber mixture produced at different lower temperatures with the warm mix asphalt additive (AR-WMA) and identical composition was studied. The mixing temperatures were between 140 and $170^{\circ} \mathrm{C}$, being compacted at $10^{\circ} \mathrm{C}$ below (between 130 and $160^{\circ} \mathrm{C}$ ).

The equipment used to obtain in the laboratory the AR binder, mixing CRM with hot bitumen, and to mix the WMA additive with the AR binder was: a) Mixer unit (IKA Ultra-Turrax T50 digital, with a propeller agitator), maximum velocity $15000 \mathrm{rpm}$, max. viscosity $5000 \mathrm{mPas}$ (Fig. 2); b) oil bath (max. $225^{\circ} \mathrm{C}$, with temperature probe, stability and accuracy $\pm 1.0^{\circ} \mathrm{C}$ ) and 1-L metal container; c) automatically-controlled thermostatic bath (Selecta), range $5-200^{\circ} \mathrm{C}$, stability and accuracy $\pm 1.0^{\circ} \mathrm{C}$, filled with melted paraffin.

To produce the AR35/50 binder, each 50/70 bitumen sample of $600 \mathrm{~g}$ was heated at $180^{\circ} \mathrm{C}$ and then $10 \%$ (by wt.) of CRM was added in the blending unit with the oil-bath. It was then mixed during $60 \mathrm{~min}$ at $4000 \mathrm{rpm}$ at a constant temperature of $180^{\circ} \mathrm{C}$ so that the ultraviolet inhibitors, anti-oxidants and other chemicals in the tyre rubber are transferred to the asphalt, including its elastomeric properties. This gives a reacted AR binder of higher consistency. To manufacture the AR-WMA, $0.5 \%$ (referred to the bitumen weight) of Cecabase $\mathrm{RT}^{\circledR}$ liquid additive was carefully added to the bitumen and the blend was subsequently mixed for $10 \mathrm{~min}$ at $4000 \mathrm{rpm}$ and $180^{\circ} \mathrm{C}$, ensuring that the additive was properly incorporated into the binder (Fig. 2).

The Ref. HMA was produced in the laboratory by heating the

Table 1

Characterization properties of the aggregate fractions.

\begin{tabular}{|c|c|c|c|c|}
\hline \multirow[t]{2}{*}{ Type } & \# 10-20 mm & \# 4-10 mm & \# $0-4 \mathrm{~mm}$ & \multirow{2}{*}{$\frac{\text { Mineral filler }(\#<0.063 \mathrm{~mm})}{100 \% \text { CEM II/B-P } 32.5 \mathrm{R}[\mathrm{EN} 197-1]}$} \\
\hline & \multicolumn{3}{|c|}{ Vesiculated grey basalt (B-V) with scoriaceous nature } & \\
\hline$\%$ (by wt. of the total aggregate) & 20.93 & 36.27 & 38.88 & 3.92 \\
\hline$\rho_{\mathrm{a}} / \rho_{\mathrm{SSD}} / \rho_{\mathrm{rd}}[\mathrm{EN} 1097-6]\left(\mathrm{Mg} / \mathrm{m}^{3}\right)$ & $2.89 / 2.63 / 2.35$ & $2.88 / 2.56 / 2.37$ & $2.45 / 2.36 / 2.23$ & - \\
\hline $\mathrm{WA}_{24}[\mathrm{EN} 1097-6](\%)$ & 5.8 & 8.3 & 15.5 & - \\
\hline FI [EN 933-3] & 6 & 6 & - & - \\
\hline $\mathrm{SE}_{4}$ [EN 933-8] & - & - & 73 & - \\
\hline LA [EN 1097-2] & 29 & 28 & - & - \\
\hline $\mathrm{M}_{\mathrm{DE}}[\mathrm{EN} 1097-1]$ & 17 & 23 & - & - \\
\hline PSV [EN 1097-8] & 60 & 60 & - & - \\
\hline
\end{tabular}

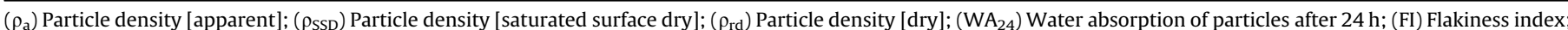

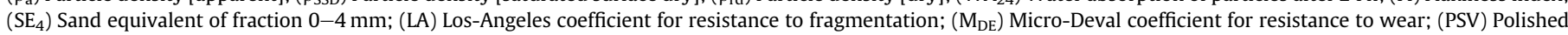
stone value for resistance to polishing. 

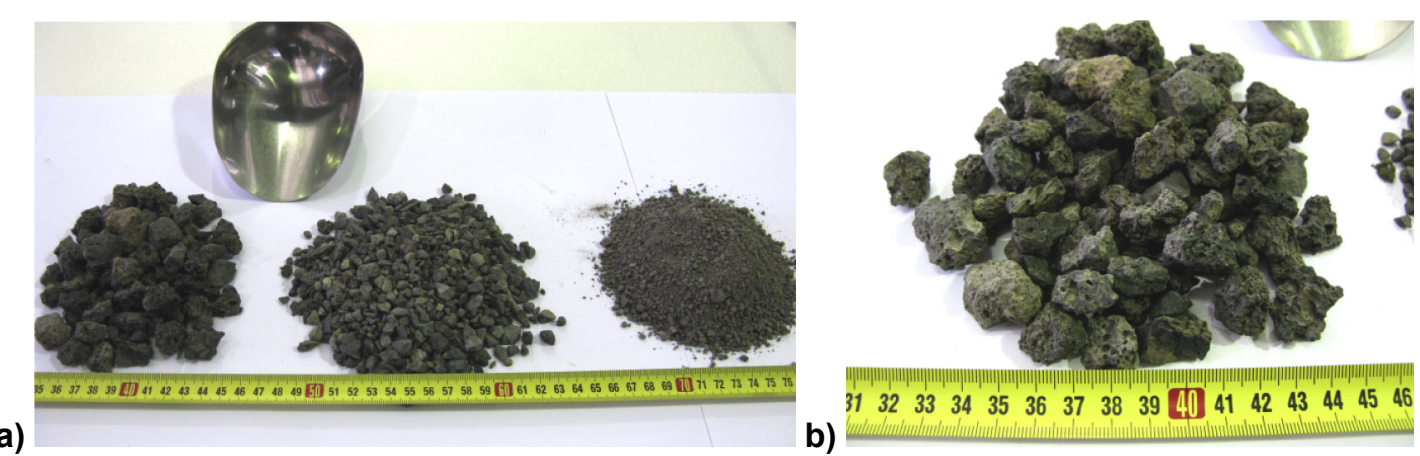

Fig. 1. Aggregate from high-porosity scoriaceous and vesiculated basalt: a) Fractions (10-20, $4-10$ and $0-4 \mathrm{~mm})$; b) Detail of the coarsest fraction.

Table 2

Characterization properties of the asphalt binders used for the different types of mixtures.

\begin{tabular}{|c|c|c|c|c|}
\hline & & Ref. HMA & Ref. AR-HMA & AR-WMA \\
\hline \multicolumn{2}{|l|}{ Binder type } & $35 / 50$ & $\mathrm{AR} 35 / 50^{(*)}$ & AR35/50 $+0.5 \%^{(* *)}$ of Cecabase $\mathrm{RT}^{(\mathbb{R}}$ \\
\hline \multicolumn{2}{|c|}{ Binder content (\% by total weight of mixture) } & 6.0 & 6.0 & 6.0 \\
\hline \multicolumn{2}{|c|}{ Density [EN 15326] $\left(\mathrm{Mg} / \mathrm{m}^{3}\right)$} & 1.042 & 1.028 & 1.027 \\
\hline \multicolumn{2}{|c|}{ Pen [EN 1426] (x10 $\left.{ }^{-1} \mathrm{~mm}\right)$} & 44 & 38 & 30 \\
\hline \multicolumn{2}{|c|}{ Softening point [EN 1427] $\left({ }^{\circ} \mathrm{C}\right)$} & 51.6 & 64.2 & 67.4 \\
\hline \multirow[t]{3}{*}{ Viscosity [EN 13302] (cP) } & at $60^{\circ} \mathrm{C}$ & 51,000 & 215,000 & 211,000 \\
\hline & at $135^{\circ} \mathrm{C}$ & 600 & 2100 & 2000 \\
\hline & at $150^{\circ} \mathrm{C}$ & 250 & 900 & 850 \\
\hline
\end{tabular}

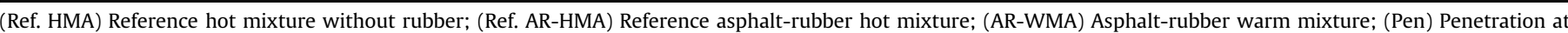

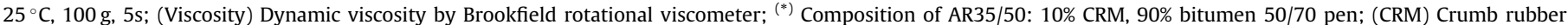
modifier; ${ }^{(* *)} \%$ by weight of the bitumen.

Table 3

Aggregate gradation and specified grading envelope for semi-dense asphalt concrete (AC16 S).

\begin{tabular}{|c|c|c|}
\hline Particle size [EN 933-2] (mm) & $\%$ passing & Limits of the specified grading envelope (\% passing) [PG-3, Spanish Ministry of Infrastructures, 2014)] \\
\hline 22 & 100.00 & $100-100$ \\
\hline 16 & 96.98 & $90-100$ \\
\hline 8 & 68.85 & $60-75$ \\
\hline 4 & 44.71 & $35-50$ \\
\hline 2 & 30.24 & $24-38$ \\
\hline 0.5 & 15.53 & $11-21$ \\
\hline 0.25 & 10.07 & $7-15$ \\
\hline 0.063 & 3.92 & $3-7$ \\
\hline
\end{tabular}

aggregates and the bitumen $35 / 50$ pen to $170{ }^{\circ} \mathrm{C}$ (aggregates were heated for $8 \mathrm{~h}$ and bitumen $3 \mathrm{~h}$ ). Subsequently, both were mixed for 1 min coating by hand followed by 2 min in the mixer. The final temperature in the mixer was $170^{\circ} \mathrm{C}$ (in no case less than $165^{\circ} \mathrm{C}$ ) and the compaction temperature $160^{\circ} \mathrm{C}$ (no less than $155^{\circ} \mathrm{C}$ ).

As for the Ref. AR-HMA, due to the higher viscosity of the AR35/ 50 binder, the heating temperature of aggregates and bitumen was $180^{\circ} \mathrm{C}$ and both were in the mixer unit for $3 \mathrm{~min}$. In this case the final temperature in the mixer was $180^{\circ} \mathrm{C}$ (no less than $175^{\circ} \mathrm{C}$ ) and compaction at $170^{\circ} \mathrm{C}$ (no less than $165^{\circ} \mathrm{C}$ ).

Finally, the AR-WMA was mixed between 140 and $170^{\circ} \mathrm{C}$ and compacted between 130 and $160^{\circ} \mathrm{C}$ on account of the chemical additive. Compaction was always carried out at $10^{\circ} \mathrm{C}$ below the corresponding mixture temperature (Fig. 3). Both the aggregates and the AR binder (with the additive formerly incorporated) were previously heated at the same temperature (the required mixing temperature), then coated with the bitumen for $1 \mathrm{~min}$ followed by $2 \mathrm{~min}$ in the mixer.

The cylindrical specimens $(D=101.6 \mathrm{~mm} ; \mathrm{h}=63.5 \mathrm{~mm}$ ) were compacted using a Marshall hammer according to EN 12697-30 with 50 or 75 blows per side (depending on the laboratory test). The slab specimens of $300 \times 300 \times 60 \mathrm{~mm}$ were compacted by rolling according to EN 12697-33 (see Fig. 4).

The compacted specimens and non-compacted samples underwent until three series of characterization tests for each type of mixture and production temperature: a) Volumetric properties of bituminous specimens: bulk density (EN 12697-6, Proced. B: saturated surface dry, and Proced. D: geometric), theoretical maximum density (EN 12697-5, Proced. A: volumetric) and void characteristics (EN 12697-8); b) Water sensitivity (EN 12697-12, by indirect tensile test [EN 12697-23]); c) Resistance to permanent deformation: wheel tracking test (EN 12697-22, Proced. B: in air, small device, at $60^{\circ} \mathrm{C}$ and $10^{4}$ cycles) and Marshall test (EN 1269734). All in all, a total of 290 laboratory specimens and samples were tested, with a total number of 18 tests on the Ref. HMA (without rubber), 18 on the Ref. AR-HMA and 36 on the AR-WMA at different production temperatures. When necessary, the different test samples were previously conditioned in a heater-refrigerator in order to reach the normalized temperature according to standards and maintained during the test if mandatory.

\section{Results and discussion}

The results of the different characterization properties were 


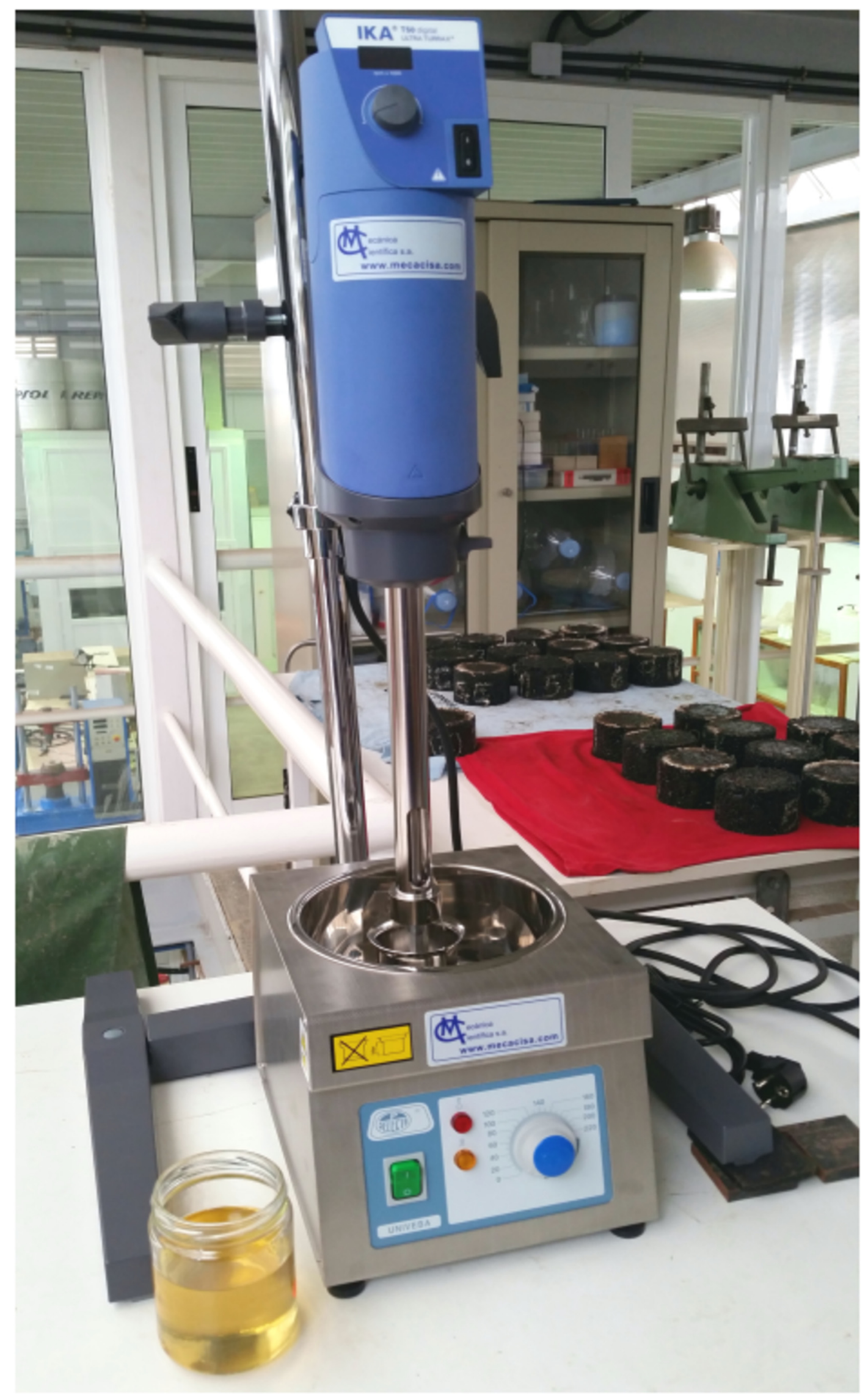

Fig. 2. Mixer unit employed to prepare the AR binder containing WMA additive. In the foreground, liquid WMA additive. 

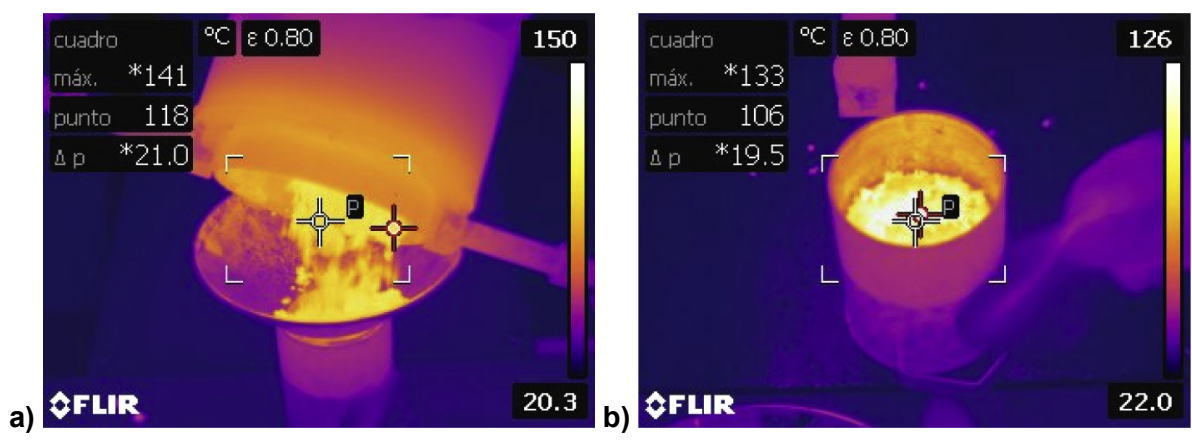

Fig. 3. Infrared thermal images of AR-WMA cylindrical specimen production: a) Mixing temperature: $140^{\circ} \mathrm{C}$; b) Compaction temperature: $130{ }^{\circ} \mathrm{C}$.

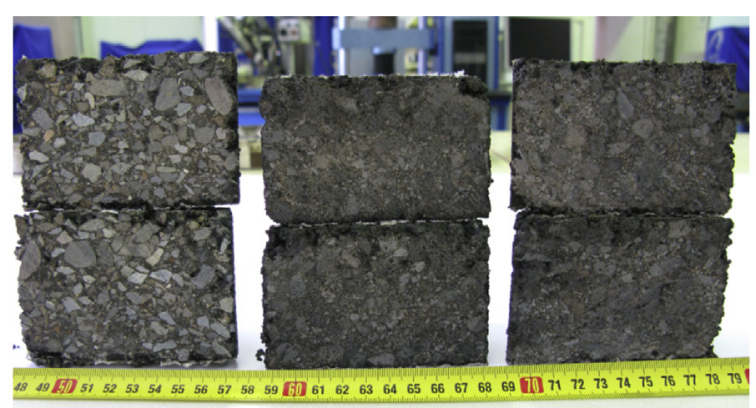

a) b)

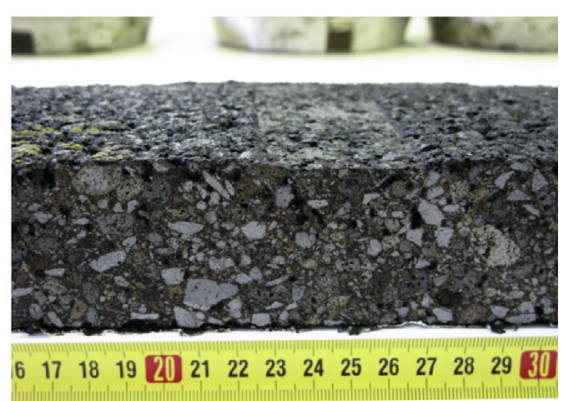
(1)

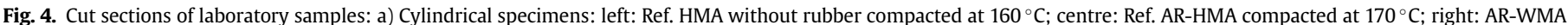
compacted at $140^{\circ} \mathrm{C}$; b) Prismatic specimen of AR-WMA compacted at $140^{\circ} \mathrm{C}$.

plotted in relation to the compaction temperature, as these properties not only depend on the mixing temperature (crucial this last in order to achieve an adequate coating of the aggregates with the bitumen) but also on the lowest temperature reached before the end of production. This coincides with the final compaction due to the temperature loss after leaving the mixer and it is critical in order to attain sufficient density. It is necessary to note that the compaction temperature was always $10^{\circ} \mathrm{C}$ lower than the corresponding mixing temperature, so results can also be directly read from the graphics as a function of this last temperature if preferred.

\subsection{Volumetric properties}

The study of volumetric characteristics is normally the first stage in the formulation of a bituminous mixture because these properties are decisive in its design and performance. An excessive air void content may be the main cause of accelerated water damage (Varveri et al., 2014) and lower fatigue life (Ma et al., 2016). In contrast, asphalt mixtures with very low air void content can cause excessive plastic deformations due to traffic loads.

The bulk density of the reference asphalt-rubber hot mixture (Ref. AR-HMA) cylindrical specimens (mixed at $180^{\circ} \mathrm{C}$ and compacted at $170^{\circ} \mathrm{C}$ by impact with 75 blows/side) is slightly superior to the reference hot mixture with conventional bitumen (Ref. HMA, mixed at $170^{\circ} \mathrm{C}$ and compacted at $160^{\circ} \mathrm{C}$ ). There was a $1.6 \%$ difference when the bulk density was measured by saturated surface dry (SSD) procedure and $0.7 \%$ if determined by geometric procedure (Fig. 5b and c, respectively). Although all mixtures were made with the same binder content (see Table 2), the theoretical maximum density of the Ref. AR-HMA was superior to the Ref. HMA (2.2\% higher) (Fig. 5a).

In Fig. 5b and $\mathrm{c}$ it can be observed that the bulk density of the asphalt-rubber warm mixture (AR-WMA) decreases as manufacturing and compaction temperatures become lower. ARWMA densities were lower than the Ref. AR-HMA when compacted below $150^{\circ} \mathrm{C}$, whilst they maintained higher densities than conventional Ref. HMA without rubber as long as compaction temperature stayed above $135-140^{\circ} \mathrm{C}$. Densities calculated by SSD procedure were always higher than those obtained by geometric method. The theoretical maximum density of the AR-WMA noncompacted samples did not vary significantly with the different temperatures studied and was higher than both reference mixtures (Fig. 5a).

Table 4 summarizes the averages of the statistical dispersion parameters for the results of the different properties tested. Bulk densities obtained for the three types of mixtures in all tests proved to be homogeneous, especially in the AR mixtures (Coefficient of variation: $\mathrm{CV} \leq 2.1 \%$, for $\mathrm{AR}-\mathrm{WMA}$; $\mathrm{CV} \leq 1.7 \%$, for Ref. AR-HMA; $\mathrm{Cv} \leq 3.0$ for Ref. HMA).

Fig. 6 summarizes the void characteristics of the same cylindrical specimens calculated by SSD bulk densities. In Fig. 7 these void characteristic were obtained by geometric bulk densities. The air void content $\left(\mathrm{V}_{\mathrm{m}}\right)$ and voids in mineral aggregate (VMA) of the Ref. AR-HMA turned out to be slightly superior than the reference hot mixture without rubber (Ref. HMA) for the same compaction energy (by impact with $2 \times 75$ blows), although the bulk density of the former also resulted slightly higher. This is due to the superior theoretical maximum density of the AR mixture, as stated before. $\mathrm{V}_{\mathrm{m}}$ difference was between $0.6 \%$ by SSD procedure (Fig. $6 \mathrm{a}$ ) and $1.4 \%$ by geometric procedure (Fig. 7a). The superior porosity of the AR mixture also suggests a more difficult compaction due to the higher viscosity of the AR binder, even though mixed and compacted at a temperature $10^{\circ} \mathrm{C}$ higher. This fact was also observed during laboratory production of AR mixtures. Pérez and Pasandín (2017) obtained similar results in mixtures with the same type of binder but with recycled concrete aggregates. Figs. $6 \mathrm{c}$ and $7 \mathrm{c}$ show the 


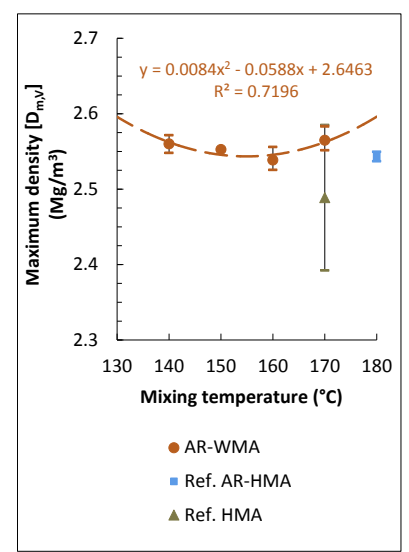

a)

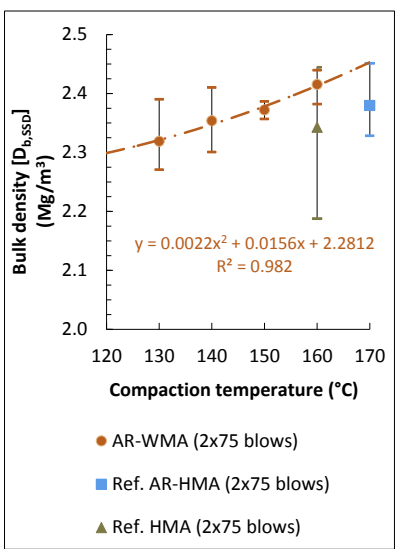

b)

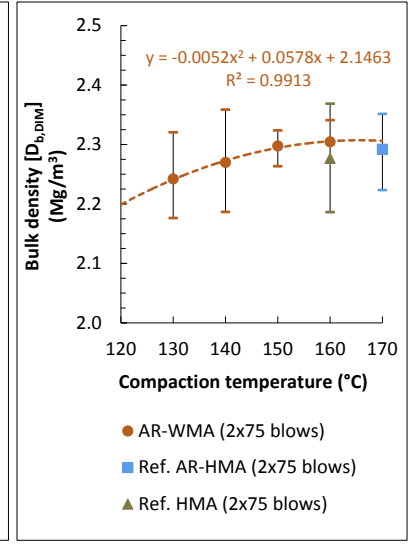

c)

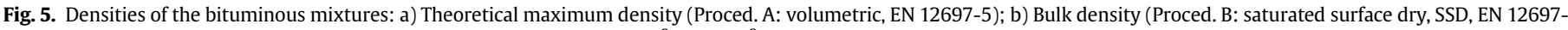
$6)$; c) Bulk density (Proced. D: geometric, EN 12697-6). (Note that $1 \mathrm{Mg} / \mathrm{m}^{3}=1 \mathrm{~g} / \mathrm{cm}^{3}$ ).

\section{Table 4}

Statistical dispersion parameters for the different properties tested.

\begin{tabular}{|c|c|c|c|c|c|c|}
\hline \multirow[t]{2}{*}{ Property of the mixture } & \multicolumn{2}{|l|}{ Ref. HMA } & \multicolumn{2}{|l|}{ Ref. AR-HMA } & \multicolumn{2}{|l|}{ AR-WMA } \\
\hline & Sd & $\mathrm{Cv}(\%)$ & Sd & $\mathrm{Cv}(\%)$ & $\mathrm{Sd}$ & $\mathrm{Cv}(\%)$ \\
\hline $\mathrm{D}_{\mathrm{m}, \mathrm{V}}$ & $0.10 \mathrm{Mg} / \mathrm{m}^{3}$ & 3.98 & $0.03 \mathrm{Mg} / \mathrm{m}^{3}$ & 0.99 & $0.02 \mathrm{Mg} / \mathrm{m}^{3}$ & 0.62 \\
\hline $\mathrm{D}_{\mathrm{b}, \mathrm{SSD}}(2 \times 75$ blows $)$ & $0.06 \mathrm{Mg} / \mathrm{m}^{3}$ & 2.74 & $0.04 \mathrm{Mg} / \mathrm{m}^{3}$ & 1.71 & $0.05 \mathrm{Mg} / \mathrm{m}^{3}$ & 1.94 \\
\hline $\mathrm{D}_{\mathrm{b}, \mathrm{DIM}}(2 \times 75$ blows $)$ & $0.07 \mathrm{Mg} / \mathrm{m}^{3}$ & 3.03 & $0.03 \mathrm{Mg} / \mathrm{m}^{3}$ & 1.45 & $0.05 \mathrm{Mg} / \mathrm{m}^{3}$ & 2.13 \\
\hline ITSR & $6.53 \%$ & 9.32 & $11.18 \%$ & 12.86 & $5.35 \%$ & 5.66 \\
\hline ITSw & $0.37 \mathrm{MPa}$ & 33.19 & $0.21 \mathrm{MPa}$ & 15.78 & $0.11 \mathrm{MPa}$ & 10.31 \\
\hline ITSd & $0.44 \mathrm{MPa}$ & 27.89 & $0.11 \mathrm{MPa}$ & 7.48 & $0.24 \mathrm{MPa}$ & 19.63 \\
\hline WTS $_{[\text {air] }}$ & $0.19 \mathrm{~mm} / 10^{3}$ cycles & 46.47 & $0.05 \mathrm{~mm} / 10^{3}$ cycles & 58.87 & $0.08 \mathrm{~mm} / 10^{3}$ cycles & 41.48 \\
\hline $\mathrm{RD}_{[\text {air] }}$ & $1.66 \mathrm{~mm}$ & 26.53 & $0.58 \mathrm{~mm}$ & 32.08 & $0.62 \mathrm{~mm}$ & 19.34 \\
\hline $\mathrm{PRD}_{\text {[air] }}$ & $1.76 \%$ & 14.24 & $1.34 \%$ & 40.93 & $1.07 \%$ & 19.24 \\
\hline Marshall S & $0.87 \mathrm{kN}$ & 12.75 & $2.06 \mathrm{kN}$ & 12.24 & $2.05 \mathrm{kN}$ & 16.69 \\
\hline Marshall F & $0.29 \mathrm{~mm}$ & 9.99 & $0.29 \mathrm{~mm}$ & 10.93 & $1.11 \mathrm{~mm}$ & 28.89 \\
\hline Marshall (S/F) & $0.31 \mathrm{kN} / \mathrm{mm}$ & 13.23 & $1.23 \mathrm{kN} / \mathrm{mm}$ & 18.36 & 1.36 & 38.61 \\
\hline
\end{tabular}

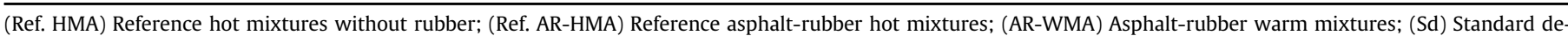
viation; (Cv) Coefficient of variation.

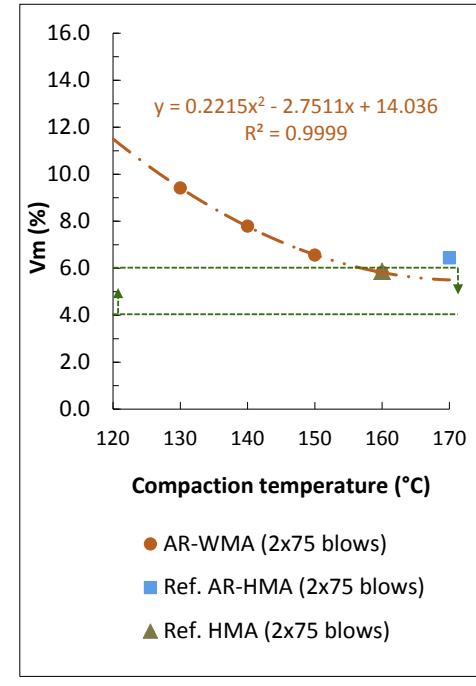

a)

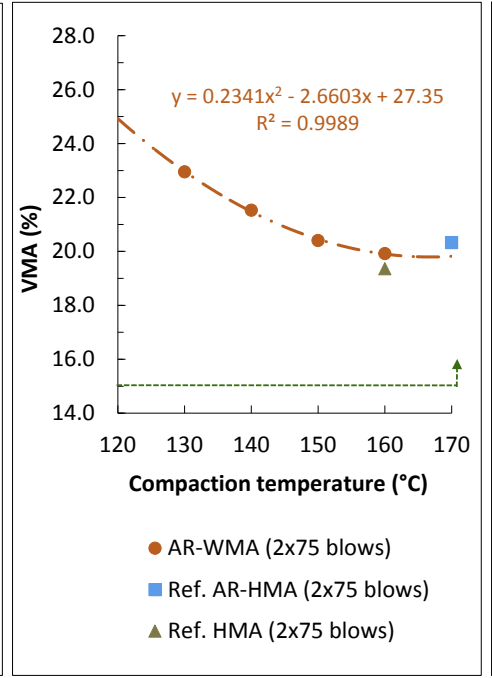

b)

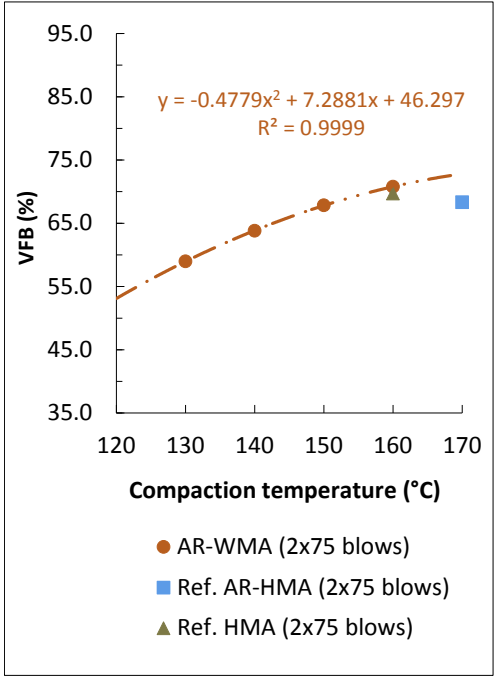

c)

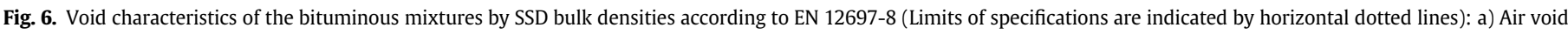
content in the mixture; b) Voids in mineral aggregate; c) Voids filled with bitumen. 


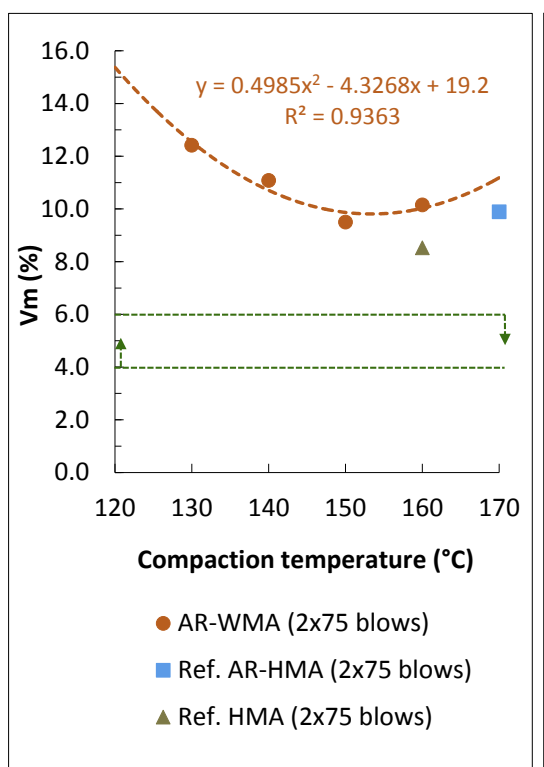

a)

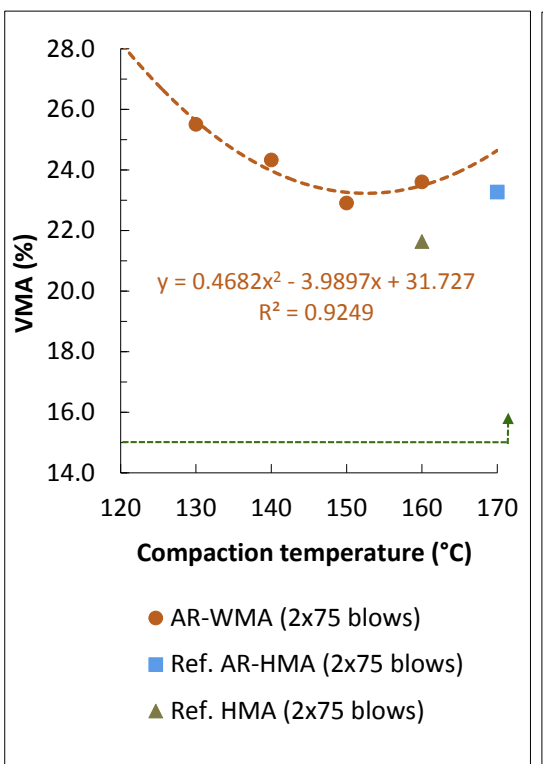

b)

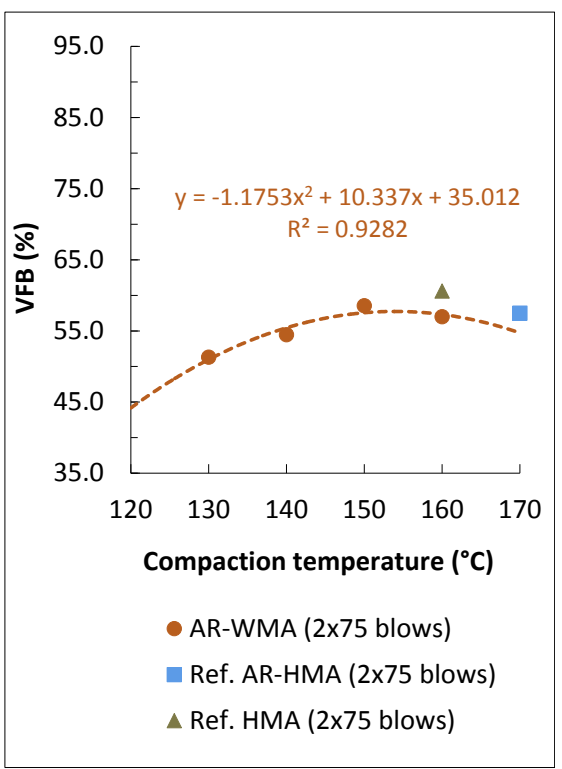

c)

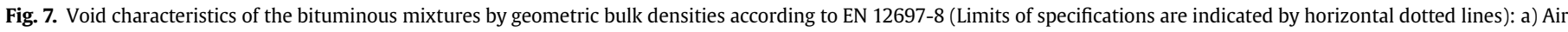
void content in the mixture; b) Voids in mineral aggregate; c) Voids filled with bitumen.

percentage of voids filled with bitumen (VFB), being slightly lower in case of AR mixtures (1.4-3.1\%, respectively).

As for the AR-WMA, Fig. 6 also shows that both $V_{m}$ and VMA resulted higher as the compaction temperature decreases. Similar or inferior air void contents were obtained to both reference mixtures if compaction temperatures are over $150^{\circ} \mathrm{C}$. It is also worth noting that there is an almost perfect experimental value adjustment to the functions obtained by non-linear regression (coefficients of determination $\mathrm{R}^{2}$ close to 1 ). However, when these void characteristics were calculated with bulk densities obtained by the geometric procedure, in all cases they resulted superior to those obtained by SSD procedure and with the minimum value for $150{ }^{\circ} \mathrm{C}$ (Fig. 7).

Void characteristics of AR-WMA, complied with the specifications of the Spanish standards for roads (PG-3, Spanish Ministry of Infrastructures, 2014) $(4 \leq \mathrm{Vm} \leq 6 \%$ and VMA $\geq 15 \%$, for $\mathrm{AC}$ in surface layers, specimens compacted with $2 \times 75$ blows and voids determined by SSD procedure) for compaction temperatures equal and superior to $155^{\circ} \mathrm{C}$.

\subsection{Water sensitivity}

Fig. 8a shows the enhancement of water action resistance on cylindrical specimens compacted by impact with 50 blows/side by means of the indirect tensile strength ratio (ITSR). ITSR represents the quotient between the average indirect tensile resistance at $15^{\circ} \mathrm{C}$ of a certain water-saturated (during $72 \mathrm{~h}$ at $40^{\circ} \mathrm{C}$ ) specimen subset $\left(\mathrm{ITS}_{\mathrm{w}}\right)$ and the corresponding dry specimen subset $\left(\mathrm{ITS}_{\mathrm{d}}\right)$ at the same temperature, according to European Standard EN 1269712. The ITSR of the reference asphalt-rubber hot mixture (Ref. ARHMA, mixed at $180^{\circ} \mathrm{C}$ and compacted at $170{ }^{\circ} \mathrm{C}$ ) resulted $24.1 \%$ higher than the reference hot mixture with conventional bitumen (Ref. HMA, mixed at $170^{\circ} \mathrm{C}$ and compacted at $160^{\circ} \mathrm{C}$ ). Indirect tensile strength of water-saturated cylindrical specimens $\left(\right.$ ITS $\left._{\mathrm{w}}\right)$ of the Ref. AR-HMA was (27.0\%) superior compared to the Ref. HMA (Fig. 8b). However, this indirect tensile resistance was similar for dry specimens $\left(\mathrm{ITS}_{\mathrm{d}}\right.$, Fig. 8c). This result proves the higher resistance to moisture damage that the asphalt-rubber (AR) produces in mixtures with high-porosity marginal volcanic aggregates. This result is noteworthy since previous research with other marginal aggregates (recycled concrete aggregates) reported a lower water damage resistance for AR mixtures (Pérez and Pasandín, 2017).

As for AR-WMA, the ITSR is clearly reduced with the temperature of the mixture although road specifications are met (for AC in surface layers: ITSR $\geq 85 \%$ ) as long as the compaction temperature remains above $140{ }^{\circ} \mathrm{C}$. The improvement of ITSR remains at all temperatures studied compared to the same mixture without rubber thanks to the AR binder. However, this improvement reduces as the temperature drops (Fig. 8a). At $160^{\circ} \mathrm{C}$ the ITSR proved to be superior compared to both reference mixtures (30.2\% superior to Ref. HMA and even 6.1\% superior to Ref. AR-HMA, this last compacted at $170^{\circ} \mathrm{C}$ ), possibly due to the anti-stripping properties of the surfactant additive.

ITS $_{\mathrm{W}}$ of AR-WMA proved to be similar to the reference mixtures up to temperatures not below $150-160^{\circ} \mathrm{C}$ (Fig. $8 \mathrm{~b}$ ). On the contrary, ITS $_{\mathrm{d}}$ of AR-WMA was inferior compared to both reference mixtures at all temperatures (Fig. $8 \mathrm{c}$ ). Consequently, the chemical additive managed to partially maintain the improvement regarding resistance to water action on these mixtures with high porosity aggregates and manufactured at lower temperatures. This is due to the combined effect of its surfactant properties and the properties of the rubber. This improvement was maintained as long as temperatures do not drop below $150^{\circ} \mathrm{C}$.

According to Table 4, the statistical dispersion of the laboratory test results was lower in the case of the AR mixtures $(C v \leq 19.6 \%$, for AR-WMA; $\mathrm{CV} \leq 15.8 \%$, for Ref. AR-HMA) compared to the mixtures without rubber $(\mathrm{Cv} \leq 33.2 \%)$ and Fig. 8 also shows less dispersion for indirect tensile resistance of water-saturated AR-WMA specimens $\left(\mathrm{ITS}_{\mathrm{W}}\right)$ than for dry specimens $\left(\mathrm{ITS}_{\mathrm{d}}\right)$.

\subsection{Resistance to permanent deformations}

Fig. 9 shows the evolution of the rut depth versus the number of load cycles according to wheel tracking laboratory test (proced. B: in air, small device, at $60^{\circ} \mathrm{C}$ and $10^{4}$ cycles) on slab specimens compacted with metallic roller and clearly highlights the improved 


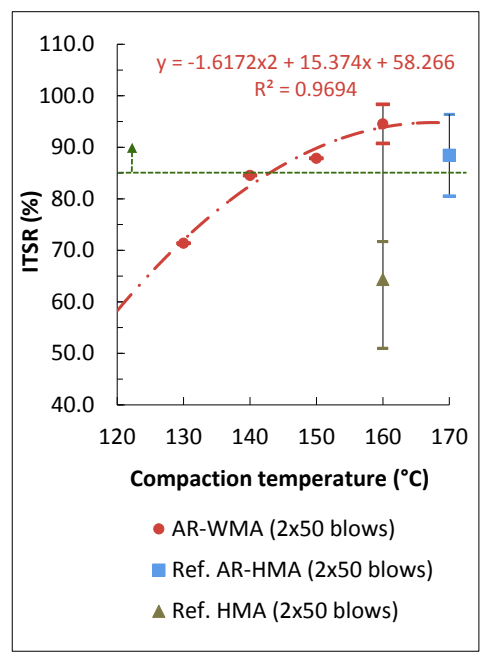

a)

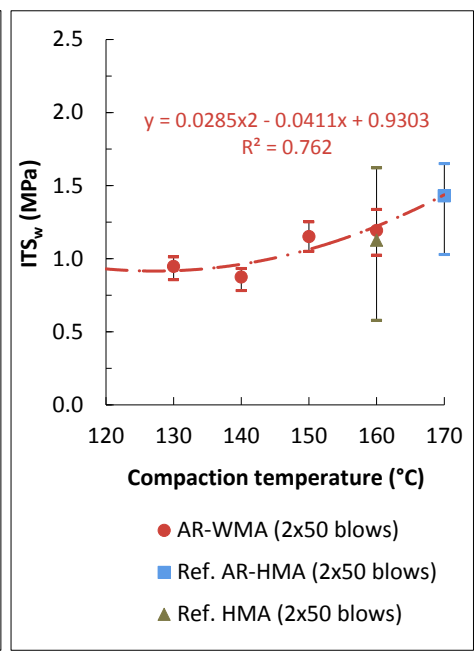

b)

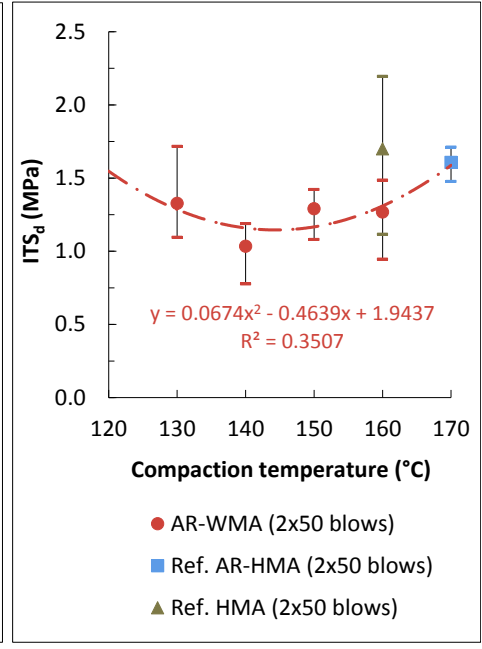

c)

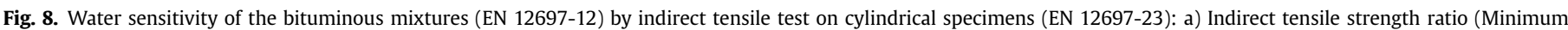
specified ITSR is shown by a horizontal dotted line); b) Indirect tensile strength of saturated specimens; c) Indirect tensile strength of dry specimens.

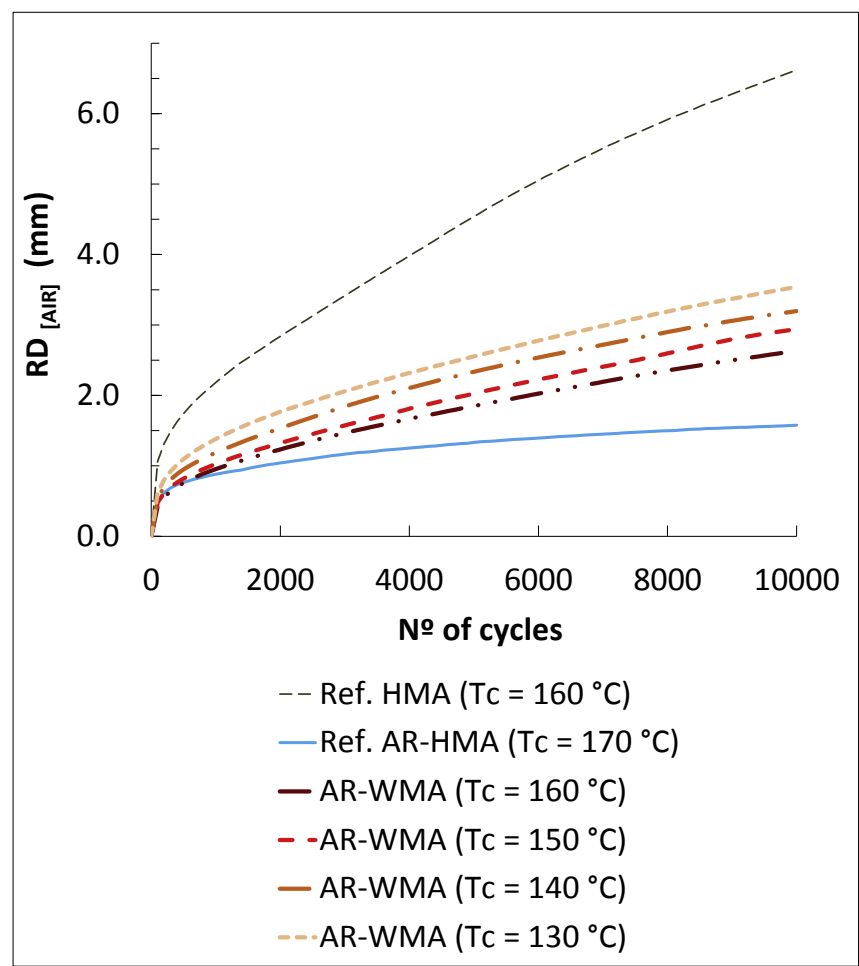

Fig. 9. Rut depth vs. number of load cycles according to wheel tracking test (Proced. B: in air, small device, at $60^{\circ} \mathrm{C}$ and $10^{4}$ cycles, EN 12697-22). (Tc: compaction temperature).

rutting resistance of the Ref. AR-HMA compared to the conventional mixture (Ref. HMA). These were both manufactured with the same bitumen content ( $6.0 \%$ by wt. of mixture) but with different production temperatures as aforementioned. This improvement of resistance to permanent deformation of the AR mixture is noteworthy: the wheel-tracking slope of the rut depth $\left(\mathrm{WTS}_{[\mathrm{air}]}\right.$ between $5 \times 10^{3}$ and $10^{4}$ load cycles) decreased by $546.0 \%$ (Fig. 10a); the rut depth ( $\mathrm{RD}_{\text {[air] }}$ at $10^{4}$ cycles) decreased by $279.6 \%$ (Fig. 10b), and the proportional rut depth ( $\mathrm{PRD}_{[\text {air] }}$ at $10^{4}$ cycles) by $8.2 \%$
(Fig. 10c). These results prove that the use of an AR binder in mixtures with this type of volcanic aggregates considerably improves the resistance to plastic deformation owing to the elastic properties of the rubber. This improvement constitutes an important practical application for construction purposes (Fig. 11).

AR-WMA slab specimens results are also shown in Figs. 9 and 10 and compared to the reference mixtures. Both wheel-tracking slope of the rut depth $\left(\mathrm{WTS}_{[\mathrm{air}]}\right)$ and rut depth $\left(\mathrm{RD}_{[\mathrm{air}]}\right)$ and proportional rut depth $\left(\mathrm{PRD}_{[\mathrm{air}]}\right)$ increased as production and compaction temperatures of AR-WMA lowered. The good regression adjustment to the functions for the rut depth and the proportional rut depth at $10^{4}$ cycles is noteworthy (Fig. 10b and c).

Therefore, these low-temperature mixtures only met technical specifications for surfaces $\left(\mathrm{WTS}_{[\text {air] }} \leq 0.10 \mathrm{~mm} / 10^{3}\right.$ cycles; $\mathrm{PRD}_{[\text {air] }} \leq 5 \%$ ) with compaction temperatures above $155^{\circ} \mathrm{C}$ (whilst WTS $_{\text {[air] }}$ limitation is only achieved above $170^{\circ} \mathrm{C}$ ). In any event, the improvement of resistance to plastic deformation that the AR have on these mixtures with marginal volcanic aggregates compared to the mixtures without rubber (Ref. HMA) remains at all the temperatures studied (Fig. 9). For instance, at $160^{\circ} \mathrm{C}$ the WTS $\mathrm{Wair]}_{\text {] }}$ of ARWMA was $117.8 \%$ inferior (more favourable) than the Ref. HMA, the $\mathrm{RD}_{\text {[air] }} 129.4 \%$ inferior and the $\mathrm{PRD}_{\text {[air] }} 6.5 \%$ inferior (Fig. 10). Nevertheless, the aforementioned improvement is reduced as the compaction temperature decreases.

The standard deviation of the $\mathrm{PRD}_{\text {[air] }}$ results was lower in the case of the AR mixtures ( $S d \leq 1.1 \%$, for AR-WMA; $S d \leq 1.3 \%$, for Ref. AR-HMA; Sd $\leq 1.8 \%$, for Ref. HMA), even though the variation coefficients were similar (Table 4). It is also worth highlighting the dispersion reduction of laboratory results as the AR-WMA production temperatures increase (Fig. 10).

Marshall tests provided similar results on cylindrical specimens compacted by impact with $2 \times 75$ blows, with a noteworthy increase of stability (152.2\%), reduction of Marshall flow value (23.9\%) and consequently an increased Marshall quotient (221.5\%) for the Ref. AR-HMA compared to the Ref. HMA without rubber. These Marshall tests on the AR-WMA specimens showed a decrease of stability and an increase of deformation as temperatures were lowered (Fig. 12). In a similar manner to the results provided by the wheel tracking tests, the improvement of the Marshall stability that the AR binder has on mixtures with this type of aggregates is maintained at all the temperatures studied. At $160^{\circ} \mathrm{C}$ the Marshall 


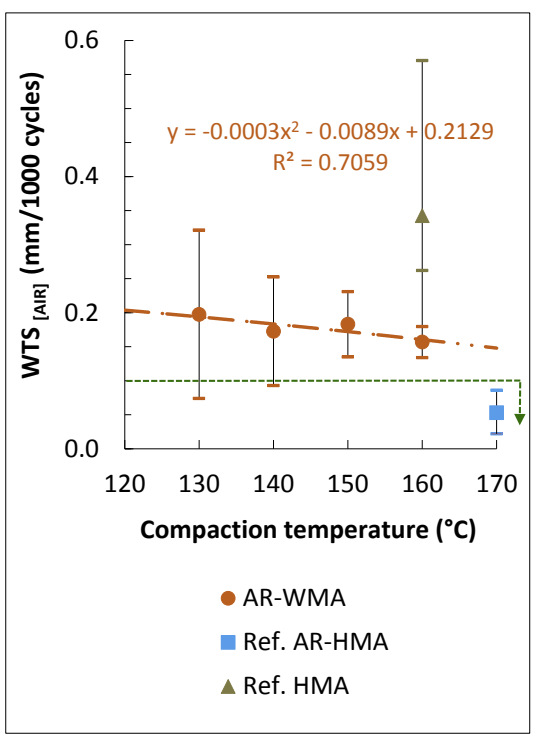

a)

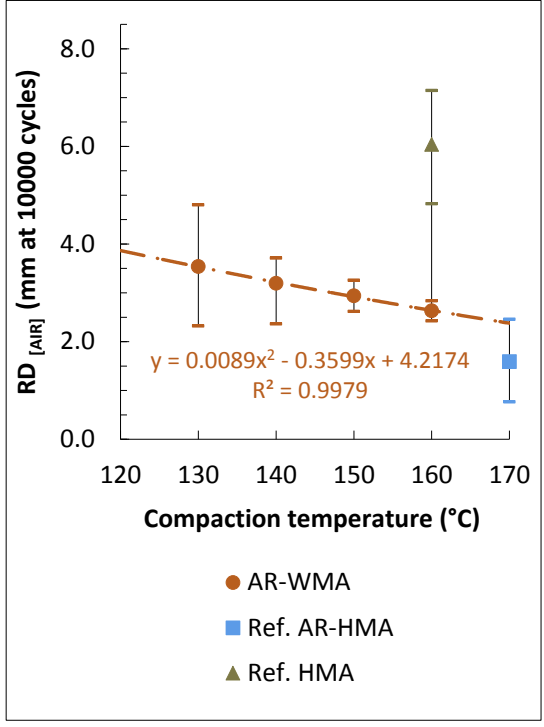

b)

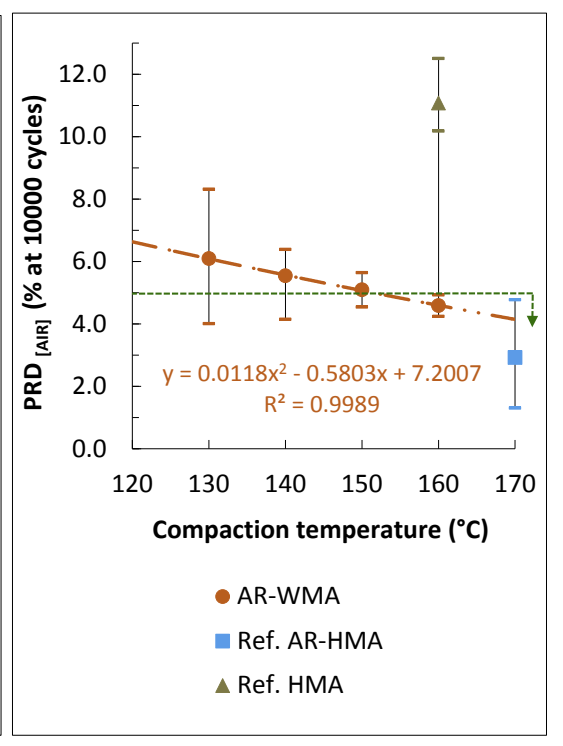

c)

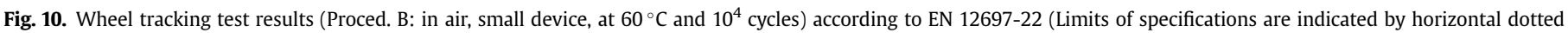
lines): a) Wheel-tracking slope between $5 \times 10^{3}$ and $10^{4}$ load cycles; b) Rut depth at $10^{4}$ cycles; c) Proportional rut depth at $10^{4}$ cycles.

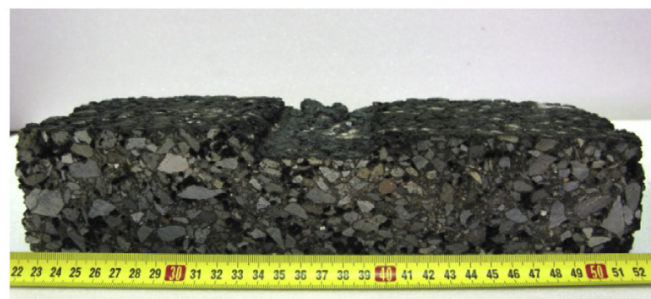

a)

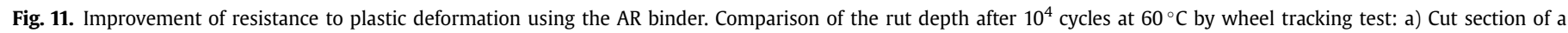
Ref. HMA slab specimen (without rubber); b) Cut section of an AR-WMA slab specimen compacted at $140^{\circ} \mathrm{C}$.

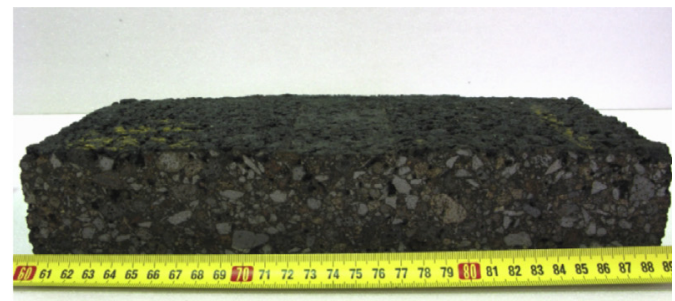

b)

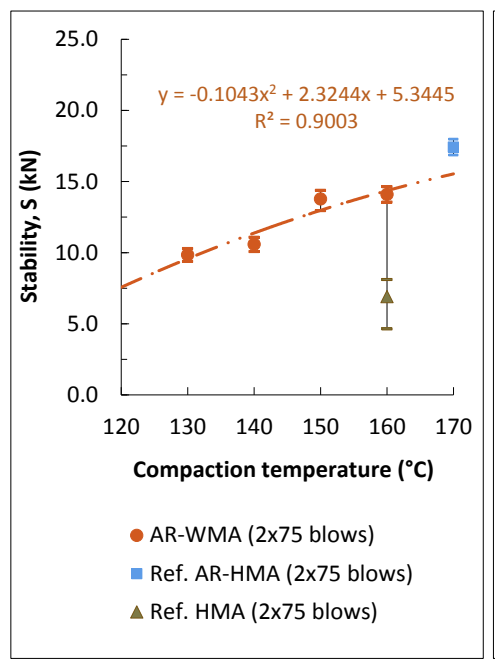

a)

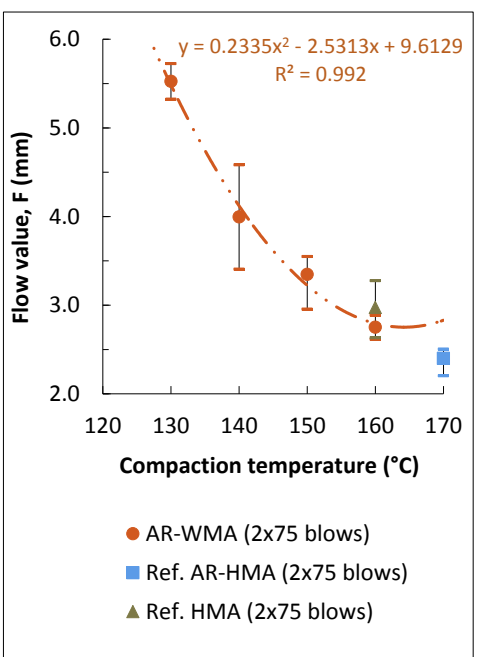

b)

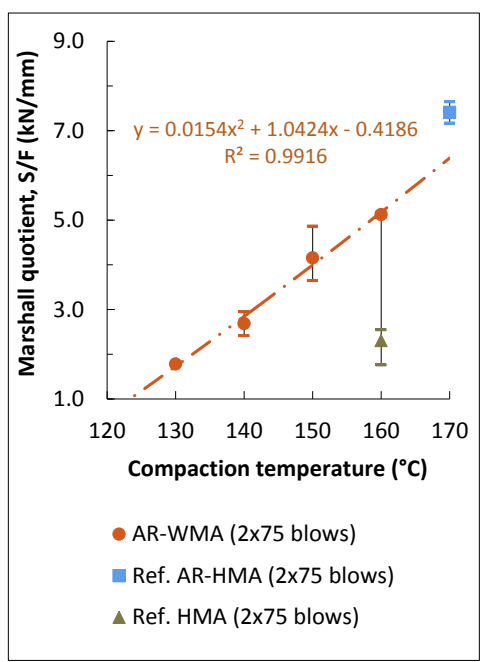

c)

Fig. 12. Marshall test results (EN 12697-34): a) Marshall stability; b) Marshall flow value; c) Marshall quotient. 
stability of the AR-WMA was $103.9 \%$ higher than the Ref. HMA and the Marshall flow value was $8.0 \%$ inferior, while the Marshall quotient continued to be $122.6 \%$ superior. However, this improvement of resistance to plastic deformation decreases as the temperature is lowered.

In this test, the statistical dispersions of the results were higher for AR-WMA ( $\mathrm{Cv} \leq 38.6 \%$, for AR-WMA; $\mathrm{CV} \leq 18.4 \%$, for Ref. ARHMA; $\mathrm{Cv} \leq 13.2 \%$, for Ref. HMA) (Table 4 ).

The dynamic stiffness modulus by indirect tensile test on cylindrical specimens compacted with $2 \times 75$ blows (IT-CY, load surface factor $\mathrm{k}=0.6$, at $20^{\circ} \mathrm{C}$ ) was also evaluated, according to Standard EN 12697-26, in order to determine the mechanical performance of these mixtures under traffic loads. The specimens of Ref. AR-HMA provided an average stiffness modulus at $20^{\circ} \mathrm{C}$ of $6044 \mathrm{MPa}$ and $6830 \mathrm{MPa}$ for Ref. HMA without rubber. Thus, both mixtures (with the same binder content of 6\%) showed sufficient stiffness for this type of asphalt concrete, though the mixture with rubber suffered a $13 \%$ of modulus reduction due to its slightly higher porosity (as stated in section 3.1), as a result of the higher viscosity of the AR binder.

\subsection{Interfacial contact of mixture components}

The improved resistance of the AR mixtures, especially to indirect tensile test of water-saturated specimens compared to the mixture without rubber, is closely linked to a superior interfacial adhesion between the binder and the aggregate particles. This can be observed in Fig. 13: cracks fracture the aggregate particles but the adhesion at the aggregate-bitumen interface is maintained (Fig. 13c and d) because of the better adherence of the AR binder. This even occurs on mixtures produced at low temperatures thanks to the use of the surfactant additive; on the contrary, on conventional mixtures cracks mainly go around the interfacial contacts (Fig. 13a and b). Moreover, the superior softening point of the AR binders (see Table 2) contributes to the reduction of the permanent deformation of these mixtures.

According to Mull et al. (2002), it seems that it may have a microstructural origin. CRM binders can increase the interfacial adhesion between the bitumen and the aggregate particles by creating more and finer microscopic ridges and well pronounced dimples with less smooth fracture surfaces. This can be observed on high resolution Scanning Electron Microscopy (SEM) images of the fracture surface. This higher degree of interlock among the mixture components could explain the micromechanical behaviour and thus, the performance enhancement of the rubberized mixtures.

\subsection{Compliance with pavement specifications}

Fig. 13 summarizes the AR-WMA production temperatures that, according to results, fulfil with standard specifications for pavements, including surface, binder and base courses. As shown on this graph, the worst compliance is with those properties regarding permanent deformations, specially the WTS $\mathrm{Wair}_{[}$. With this surfactant additive the minimum compaction temperature in order to produce this type of AR-WMA for surface layers is $165^{\circ} \mathrm{C}$ (mixing at $175^{\circ} \mathrm{C}$ ) if all the requirements must be fulfilled. However, if WTS is not so relevant or if these mixtures are used for binder or base layers, where these requirements are less strict, the compaction temperatures can be reduced to a minimum of $150-155^{\circ} \mathrm{C}$. These mixtures even maintain a satisfactory resistance to water damage if compacted over $140{ }^{\circ} \mathrm{C}$ for surface layers and $135^{\circ} \mathrm{C}$ for lower pavement layers (see Fig. 14).

\section{Conclusions}

Based on the results and discussion of this experimental research, the following conclusions can be drawn regarding semidense asphalt concrete with highly-vesiculated volcanic aggregates, produced at different temperatures:

The bulk density of the asphalt-rubber warm mixture (ARWMA) with surfactant additive decreases as production and compaction temperatures are lowered. This low-temperature mixture maintained similar densities to the AR-HMA (mixed at $180^{\circ} \mathrm{C}$ and compacted at $170^{\circ} \mathrm{C}$ ) as long as compaction is not below $150^{\circ} \mathrm{C}$, and similar to the HMA (mixed at $170^{\circ} \mathrm{C}$; compacted at $160^{\circ} \mathrm{C}$ ) if the temperature does not fall below $135-140^{\circ} \mathrm{C}$.

Consequently, both the air void content $\left(\mathrm{V}_{\mathrm{m}}\right)$ and voids in mineral aggregate (VMA) of the AR-WMA increased as manufacture temperature reduced. A void content similar to the AR-HMA and to the HMA was achieved when compaction temperatures were equal or above $155^{\circ} \mathrm{C}$. This complies with the road specifications regarding void characteristics for surface layers.

Although a significant enhancement of moisture damage resistance was noted due to the use of the AR binder, the indirect tensile strength ratio (ITSR) of the AR-WMA clearly decreases when temperatures are lowered. ITSR only meets road specifications for surfaces as long as compaction temperature is above $140^{\circ} \mathrm{C}$ Nevertheless, the improvement of ITSR owing to the AR binder is maintained at all temperatures studied: at $140^{\circ} \mathrm{C}$ the improvement still remains around $20 \%$.

Laboratory results clearly highlighted the outstandinglyimproved rutting resistance when using the AR binder. However, decreasing temperatures result in a loss of resistance to plastic deformation of the AR-WMA. These low-temperature mixtures only comply with road specifications for surface courses if compacted above $155^{\circ} \mathrm{C}$. Nevertheless, the improvement of resistance with respect to the mixture without rubber is maintained at all temperatures studied.

Similar conclusions may be drawn from the Marshall tests: the improvement of resistance to plastic deformation decreases as temperature is lowered, though at the production temperature of conventional mixtures it still remains significantly (at $160{ }^{\circ} \mathrm{C}$ the AR-WMA Marshall quotient continued to be $122.6 \%$ superior than Ref. HMA).

It is possible to produce these AR-WMA and comply with all the standard specifications for road surfaces as long as the compaction temperature remains above $160-165^{\circ} \mathrm{C}$ (mixing at $170-175^{\circ} \mathrm{C}$ ). This means a reduction of just $5-10^{\circ} \mathrm{C}$, which compensates for the higher energy consumption and emissions owing to the high viscosity of the AR binder. For lower pavement layers or where the requirements regarding plastic deformation are less strict, the compaction temperatures can be reduced to a minimum of $150-155^{\circ} \mathrm{C}$.

These AR-WMA can provide adequate performance even with compaction temperatures of $140-145^{\circ} \mathrm{C}$, meaning a reduction of the production temperature by up to $25-30^{\circ} \mathrm{C}$. This last reduction could imply lower energy use and emissions (approx. 14-18\%), safer and healthier conditions for workers, higher transport distances and laying less influenced by climatic conditions. In any case, these mixtures presented certain properties such as the water resistance, rutting resistance and stability superior to the conventional mixtures without rubber at all temperatures studied, even with a reduced proportion of crumb rubber ( $10 \%$ by bitumen weight, in this study).

The proposed methodology could contribute to better development of the environmentally protected volcanic regions by reusing waste from used tyres and marginal aggregates and extending the durability of asphalt pavements. 

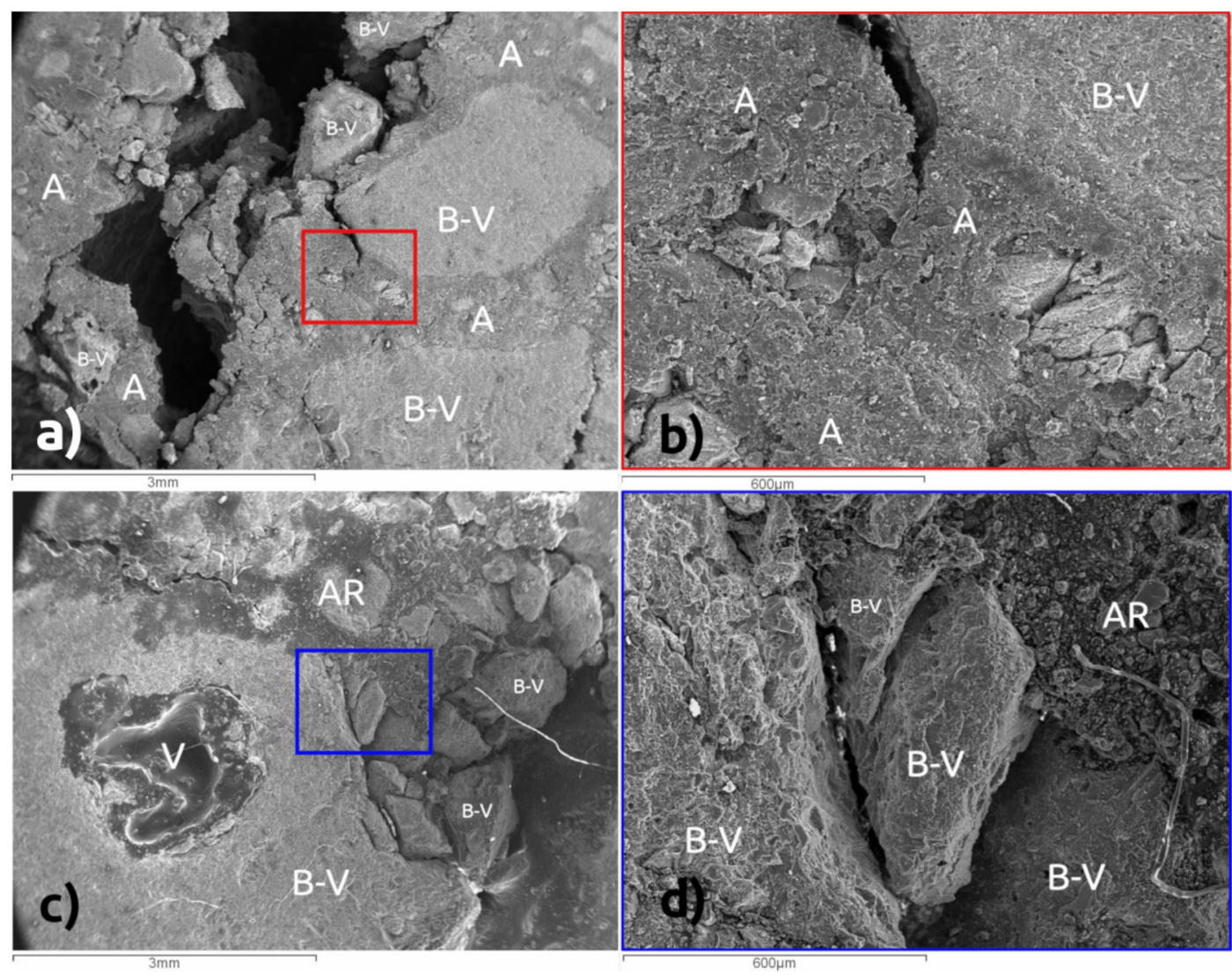

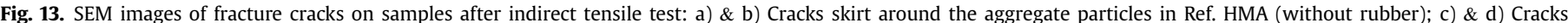
fracturing the aggregate in AR mixture. (B-V) Aggregate particle of vesicular basalt; (V) Void in aggregate particle; (A) Conventional bitumen; (AR) Asphalt-rubber bitumen.

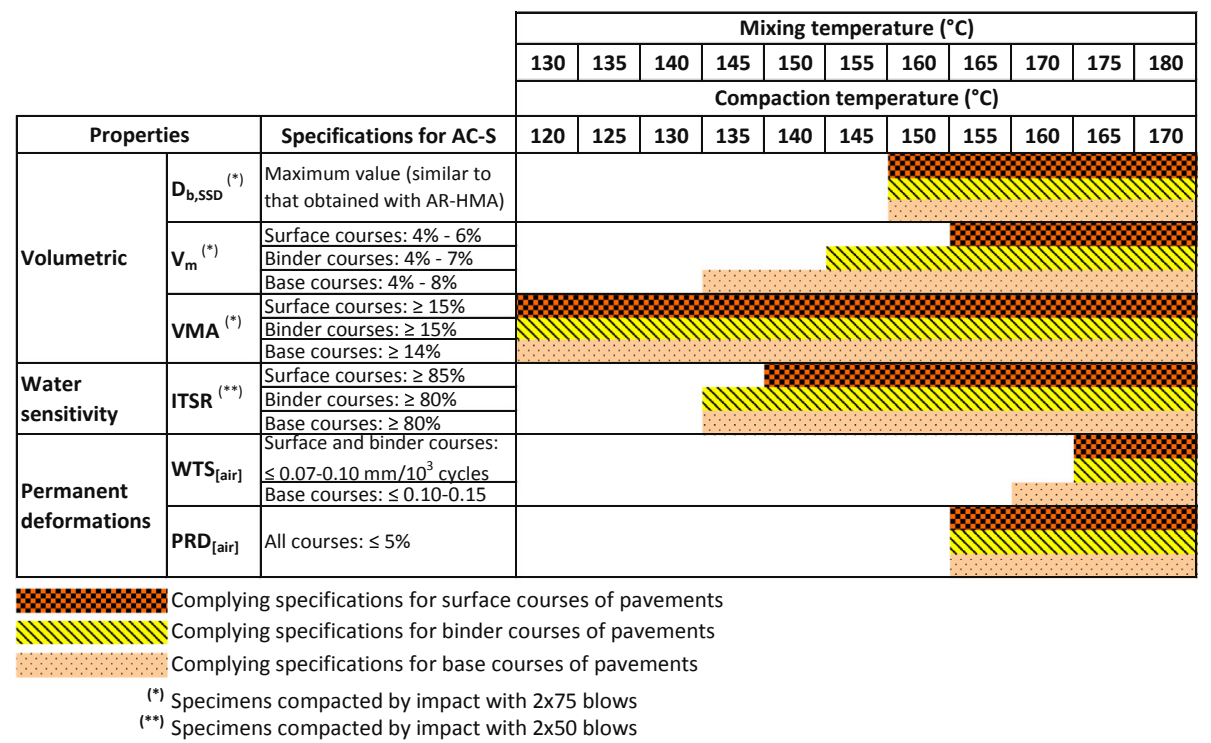

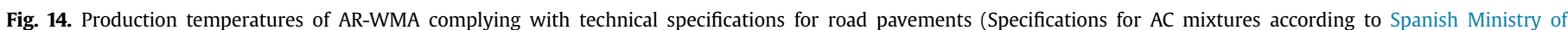
Infrastructures, 2014).

The following aspects are considered interesting for future research:

Analyse the fatigue resistance to dynamic repeated loads and durability of this type of AR-WMA, as well as its crack resistance at low temperatures.
Study reclaimed asphalt pavement (RAP) mixtures with this type of aggregates and the efficiency of the AR-WMA additives following subsequent recycling processes.

Implementation of this AR-WMA studied in the laboratory on operational roads. 


\section{Acknowledgements}

This work was supported by the Ministry of Economy and Competitiveness (MINECO) from the Government of Spain, through the following research projects: "Volcanic BC-Warm" (Ref. BIA2013-47987-C3-3-R, "Sustainable development and production of warm-mix asphalt using recycled crumb rubber from end-of-life tyres and volcanic aggregates from the Canary Islands") and "MW-VolcAsphalt" (Ref. BIA2017-86253-C2-2-R, "Sustainable self-healable perpetual asphalt pavements with volcanic aggregates using microwaves and additions of metallic wastes and nonoparticles").

The authors are also very grateful to the Port Authority of Las Palmas (María A. Bordón) for generously enabling to obtain the aggregates for this research, to the Laboratory of the Government of Canary Islands (Javier Jubera and Juana Santana) for accessing to the laboratory facilities and to the SEGAI (ULL) for obtaining the DRX analysis and the SEM images.

\section{References}

Akbulut, H., Gurer, C., Cetin, S., 2011. Use of volcanic aggregates in asphalt pavement mixes. Proc. Inst. Civ. Eng. Transp. 164, 111-123. https://doi.org/10.1680/tran. 2011.164.2.111.

Autelitano, F., Bianchi, F., Giuliani, F., 2017. Airborne emissions of asphalt/wax blends for warm mix asphalt production. J. Clean. Prod. 164, 749-756. https:// doi.org/10.1016/j.jclepro.2017.06.247.

Bonaquist, R., 2011. Mix Design Practices for Warm Mix Asphalt. National Cooperative Highway Research Program. NCHRP Report 691. Transportation Research Board, Washington DC. https://doi.org/10.17226/14488.

Edwards, Y., Redelius, P., 2003. Rheological effects of waxes in bitumen. Energy Fuel. 17 (3), 511-520. https://doi.org/10.1021/ef020202b.

Faustino, R.P., O'Connell, M.J., Valencia, N.R., Ford, W., 2005. Making effective use of volcanic ash in road-building in the Philippines. In: Proceedings of the Eastern Asia Society for Transportation Studies, vol. 5, pp. 868-876. http://citeseerx.ist. psu.edu/viewdoc/download?doi=10.1.1.543.2240\&rep=rep1\&type=pdf.

Franesqui, M.A., Castelo Branco, F., Azevedo, M.C., Moita, P., 2010. Construction experiences with volcanic unbound aggregates in road pavements. In: Olalla, et al. (Eds.), Volcanic Rock Mechanics. Taylor \& Francis Group, London, pp. 241-247. http://www.crcnetbase.com/doi/abs/10.1201/b10549-36.

Gibreil, H.A.A., Feng, C.P., 2017. Effects of high-density polyethylene and crumb rubber powder as modifiers on properties of hot mix asphalt. Construct. Build. Mater. 142, 101-108. https://doi.org/10.1016/j.conbuildmat.2017.03.062.

Jamshidi, A., Golchin, B., Hamzah, M.O., Turner, P., 2015. Selection of type of warm mix asphalt additive based on the rheological properties of asphalt binders. J. Clean. Prod. 100, 89-106. https://doi.org/10.1016/j.jclepro.2015.03.036.

Kakar, M.R., Hamzah, M.O., Valentin, J., 2015. A review on moisture damages of hot and warm mix asphalt and related investigations. J. Clean. Prod. 99, 39-58. https://doi.org/10.1016/j.jclepro.2015.03.028.

Li, X., Wang, H., Zhang, C., Diab, A., You, Z., 2016. Characteristics of a surfactant produced Warm Mix Asphalt binder and workability of the mixture. J. Test. Eval. 44 (6), 2219-2230. https://doi.org/10.1520/JTE20140447.

Liu, S., Cao, W., Fang, J., Shang, S., 2009. Variance analysis and performance evaluation of different crumb rubber modified (CRM) asphalt. Construct. Build. Mater. 23, 2701-2708. https://doi.org/10.1016/j.conbuildmat.2008.12.009.
Lo Presti, D., 2013. Recycled tyre rubber modified bitumens for road asphalt mix tures: a literature review. Construct. Build. Mater. 49, 863-881. https://doi.org 10.1016/j.conbuildmat.2013.09.007.

Ma, T., Zhang, Y., Zhang, D., Yan, J., Ye, Q., 2016. Influences by air voids on fatigue life of asphalt mixture based on discrete element method. Construct. Build. Mater. 126, 785-799. https://doi.org/10.1016/j.conbuildmat.2016.09.045.

Moreno, F., Sol, M., Martín, J., Rubio, M.C., 2013. The effect of crumb rubber modifier on the resistance of asphalt mixtures to plastic deformations. Mater. Des. 47 274-280. https://doi.org/10.1016/j.matdes.2012.12.022.

Mull, M.A., Stuart, K., Yehia, A., 2002. Fracture resistance characterization of chemically modified crumb rubber asphalt pavement. J. Mater. Sci. 37 (3) 557-566. https://doi.org/10.1023/A:1013721708572.

Naji, J.A., Asi, I.M., 2008. Performance evaluation of asphalt concrete mixes containing granular volcanic ash. J. Mater. Civ. Eng. 20, 754-761. https://doi.org/ 10.1061/(ASCE)0899-1561(2008)20:12(754).

Ouni, A.E., Dony, A., Colin, J., 2014. Probabilistic parametric approach for rutting evaluation: application to hot and warm asphalt. Int. J. Pavement Eng. 15 (1) 58-65. https://doi.org/10.1080/10298436.2012.725473.

Pérez, I., Pasandín, A.R., 2017. Moisture damage resistance of hot-mix asphalt made with recycled concrete aggregates and crumb rubber. J. Clean. Prod. 165, 405-414. https://doi.org/10.1016/j.jclepro.2017.07.140.

Rodríguez-Alloza, A.M., Gallego, J., Pérez, I., Bonati, A., Giuliani, F., 2014. High and low temperature properties of crumb rubber modified binders containing warm mix asphalt additives. Construct. Build. Mater. 53, 460-466. https://doi. org/10.1016/j.conbuildmat.2013.12.026.

Rodríguez-Alloza, A.M., Malik, A.M., Lenzen, M., Gallego, J., 2015. Hybrid inputoutput life cycle assessment of warm mix asphalt mixtures. J. Clean. Prod. 90, 171-182. https://doi.org/10.1016/j.jclepro.2014.11.035.

Rodríguez-Alloza, A.M., Gallego, J., 2017. Mechanical performance of asphalt rubber mixtures with warm mix asphalt additives. J. Mater. Struct. 50 (147). https://doi org/10.1617/s11527-017-1020-z.

Rondón-Quintana, H.A., Hernández-Noguera, J.A., Reyes-Lizcano, F.A., 2015 A review of warm mix asphalt technology: technical, economical and environmental aspects. Ing. Inv. 35, 5-18. https://doi.org/10.15446/ing.investig. v35n3.50463.

Saberi, F.K., Fakhri, M., Azami, A., 2017. Evaluation of warm mix asphalt mixtures containing reclaimed asphalt pavement and crumb rubber. J. Clean. Prod. 165, 1125-1132. https://doi.org/10.1016/j.jclepro.2017.07.079.

Sánchez, E., Vega, A., Castro, D., Del Rio, M., 2011. Evaluation of compactability and mechanical properties of bituminous mixes with warm additives. Construct. Build. Mater. 25, 2304-2311. https://doi.org/10.1016/j.conbuildmat.2010.11.024.

Shu, X., Huang, B.S., 2014. Recycling of waste tire rubber in asphalt and Portland cement concrete: an overview. Construct. Build. Mater. 67, 217-224. https://doi. org/10.1016/j.conbuildmat.2013.11.027.

Spanish Ministry of Infrastructures, 2014. General Technical Specifications for Roads and Bridges (PG-3, Art. 542 \& 543). Orden FOM/2523/2014. Madrid, Spain (in Spanish).

Varveri, A., Avgerinopoulos, S., Kasbergen, C., Scarpas, A., Collop, A., 2014. Influence of air void content on moisture damage susceptibility of asphalt mixtures: computational study. Transp. Res. Rec. J. Transp. Res. Board 2446, 8-16. https:/ doi.org/10.3141/2446-02.

Wang, S., Cheng, D., Xiao, F., 2017. Recent developments in the application of chemical approaches to rubberized asphalt. Construct. Build. Mater. 131 101-113. https://doi.org/10.1016/j.conbuildmat.2016.11.077.

Xiao, F., Punith, V.S., Amirkhanian, S.N., 2012. Effects of non-foaming WMA additives on asphalt binders at high performance temperatures. Fuel 94, 144-155. https://doi.org/10.1016/j.fuel.2011.09.017.

Yang, X., You, Z., Hasan, M.R.M., Diab, A., Shao, H., Chen, S., et al., 2017. Environmental and mechanical performance of crumb rubber modified warm mix asphalt using Evotherm. J. Clean. Prod. 159, 346-358. https://doi.org/10.1016/j. jclepro.2017.04.168. 